\title{
Association between inflammatory potential of diet and risk of depression in middle-aged women: the Australian Longitudinal Study on Women's Health
}

\author{
Nitin Shivappa ${ }^{1,2 *}$, Danielle A. J. M. Schoenaker ${ }^{3}$, James R. Hebert ${ }^{1,2}$ and Gita D. Mishra ${ }^{3}$ \\ ${ }^{1}$ Cancer Prevention and Control Program, University of South Carolina, Columbia, SC 29208, USA \\ ${ }^{2}$ Department of Epidemiology and Biostatistics, Arnold School of Public Health, University of South Carolina, Columbia, \\ SC 29208, USA \\ ${ }^{3}$ School of Public Health, University of Queensland, Brisbane, QLD 4006, Australia \\ (Submitted 2 December 2015 - Final revision received 17 June 2016 - Accepted 28 June 2016 - First published online 8 August 2016)
}

\begin{abstract}
Dietary factors and inflammation markers have been shown to play a role in the development of depression. However, there are very few studies that have explored the association between inflammatory potential of diet and risk of depression. In this study, we examined the association between the dietary inflammatory index (DII), which was developed specifically to measure the inflammatory potential of diet, and risk of depression in the middle-aged cohort of the Australian Longitudinal Study on Women's Health. A total of 6438 women with a mean age of 52.0 (sD 1.4) years at baseline were followed-up at five surveys over 12 years (2001-2013). Depression was defined as a score of $\geq 10$ on the Center for Epidemiologic Studies Depression-10 scale. The DII score, a literature-derived, population-based dietary index that has been validated against several inflammatory markers, was computed on the basis of dietary intake assessed using a validated FFQ. Generalised estimating equations were used to estimate relative risk (RR) of depression according to DII score. Models were adjusted for energy intake, highest education completed, marital status, menopause status and symptoms, personal illness or injury, smoking status, physical activity, BMI and depression diagnosis or treatment. In total, 1156 women (18\%) had scores $\geq 10$ on the CESD scale over the course of 9 years. Women with the most anti-inflammatory diet had an approximately $20 \%$ lower risk of developing depression compared with women with the most pro-inflammatory diet $\left(\mathrm{RR}_{\mathrm{DII}}\right.$ quartile $1 v$ v. $\left.4: 0.81 ; 95 \% \mathrm{CI} 0.69,0.96 ; P_{\text {trend }}=0.03\right)$. These results suggest that an anti-inflammatory diet is associated with lower risk of depression in middle-aged Australian women.
\end{abstract}

Key words: Dietary inflammatory index: Diet: Inflammation: Depression: Australia

Unipolar depression affects more than 151 million people worldwide, and it is expected to become the world's second most common disease, after CVD, by $2020^{(1)}$. Results from the Global Burden of Disease Study indicate that mental health and substance use disorders are the leading global cause for all non-fatal conditions contributing to the burden of disease, as measured by years lived with disability, with depressive disorders contributing the most to this burden of disease ${ }^{(2)}$. Women are more likely to be diagnosed with depression compared with men ${ }^{(3,4)}$. Metabolic and inflammatory processes, such as reduced insulin sensitivity, elevations in plasma homocysteine levels, increased production of pro-inflammatory cytokines, such as C-reactive protein, increased levels of stress hormones and endothelial dysfunction, appear to be the major factors responsible for depression ${ }^{(5-8)}$.

Various dietary components are known to exert different effects on inflammation ${ }^{(9-11)}$. A prudent dietary pattern high in fish, yogurt, pulses, rice, fruits, vegetables, pasta and wine has been shown to be associated with lower concentrations of intermediary inflammatory markers ${ }^{(12)}$.

Various studies have been conducted to evaluate dietary exposures in relation to depression ${ }^{(13-17)}$. In general, prospective cohort studies have shown that dietary patterns rich in components such as fruits, vegetables, olive oil and legumes may be protective against depression ${ }^{(18,19)}$. Previous results from the Australian Longitudinal Study on Women's Health (ALSWH) study showed that increased consumption of fruits reduced both the prevalence and the incidence of depressive symptoms, although no association was observed with vegetable intake ${ }^{(17)}$. In contrast, increased risk has been observed with diets rich in SFA, $n-6$ fatty acids and refined carbohydrates ${ }^{(20,21)}$. However, a few studies have explored the association between inflammatory potential of diet and depression.

A literature-derived, population-based dietary inflammatory index (DII) was developed to assess the inflammatory potential of an individual's diet ${ }^{(22)}$. Previously, higher DII scores have

Abbreviations: ALSWH, Australian Longitudinal Study on Women's Health; CESD-10, Center for Epidemiologic Studies Depression.

* Corresponding author: Dr N. Shivappa, email shivappa@mailbox.sc.edu 
been shown to be associated with increased risk of depression in a Spanish study ${ }^{(23)}$. Our aim in this study was to assess the association between the inflammatory potential of dietary patterns of middle-aged Australian women measured through DII scores and the risk of depression.

\section{Methods}

\section{Study design and participants}

ALSWH is an ongoing, population-based cohort study examining factors associated with health and well-being of Australian women. Full details on study design, recruitment methods and response rates have been published previously ${ }^{(24,25)}$. Women were randomly selected from the National Medicare Health Insurance database, including all Australian citizens and permanent residents. Women from rural and remote areas were intentionally oversampled. Informed consent was obtained from all participants at each survey, with ethics clearance obtained from the Human Research Ethics Committees of the University of Newcastle and the University of Queensland, Australia.

For this study, we used data from the middle-aged cohort of women born between 1946 and 1951. A total of 13715 women aged $45-50$ years responded to the first survey in 1996. This sample was found to be broadly representative of the general Australian population of women of similar age based on the national census ${ }^{(24)}$. Self-administered questionnaires were sent to participants every 2-3 years, until 2013 (survey 7). Response rates for surveys $2,3,4,5,6$ and 7 were $90.0 \%$ ( $n$ 12338), 81.8\% ( $n$ 11221), 79.5\% ( $n$ 10 905), $77.6 \%$ ( $n$ 10 638), $73.0 \%$ ( $n$ 10011) and $66.7 \%$ ( $n$ 9151) of baseline, respectively. Information on dietary intake was first collected at survey 3 in 2001, when women were aged 50-55 years; this survey was therefore used as baseline for this study. Women were excluded if they reported a history of depressive symptoms (Center for Epidemiologic Studies Depression (CESD-10) score of $\geq 10$ ) from survey 1 (1996) until survey 3 (2001) ( $n$ 3459), had missing data on baseline dietary intake or depressive symptoms during follow-up ( $n$ 695) or had missing data on relevant confounders ( $n$ 634). Our analyses included 6438 women (online Supplementary Fig. S1).

\section{Dietary assessment}

Diet was assessed using the Dietary Questionnaire for Epidemiological Studies (DQES) version 2. The development of this 101-item FFQ has been described elsewhere ${ }^{(26)}$. The FFQ was validated against 7 -d weighed food records in sixty-three women with a mean age of 33.3 (SD 9.5) years. Mean intakes from the weighed food records and FFQ were within $\pm 20 \%$ for twenty-one of twenty-seven nutrients ${ }^{(27)}$. Energy-adjusted correlation coefficients for nutrient intake ranged between 0.28 for vitamin $\mathrm{A}$ and 0.78 for carbohydrates, indicating that the FFQ performed reasonably well for assessing habitual intake. Participants were asked to report their usual frequency of consumption of seventy-four food items and six alcoholic beverages over the previous 12 months using a ten-point scale ranging from 'never' to 'three or more times per day'. Portion size photographs were used to adjust the serving sizes for vegetables, meat and casseroles. The FFQ included twenty-one additional items on the number of servings of milk, bread, sugar and eggs and the type of milk, bread, fat spreads and cheese consumed. Consumption of 101 food items $(\mathrm{g} / \mathrm{d})$ and nutrient intakes were computed from the national government food composition database of Australian foods the NUTTAB95 ${ }^{(28)}$.

\section{The dietary inflammatory index}

The development and validation of the DII are described in detail elsewhere ${ }^{(22,29)}$. Developing the DII involved reviewing and scoring nearly 2000 scientific articles representing cell culture and laboratory animal experiments, as well as a variety of human studies on diet and six inflammatory markers (i.e., C-reactive protein, IL-1b, IL-4, IL- 6 , IL-10, TNF- $\alpha$ ). One of three possible values was assigned to each article on the basis of the effect of the particular food or constituent on inflammation: +1 if pro-inflammatory, -1 if anti-inflammatory and 0 if it produced no change in the inflammatory marker. In addition, these articles were weighed on the basis of the study design, with experimental cell studies receiving the lowest weight of 3 and human trials the highest weight of $10^{(22,29)}$. These procedures also entailed the creation of a world standard database that involved obtaining eleven data sets from around the world (Japan, Korea, USA, Canada, Mexico, Taiwan, Australia, New Zealand, Bahrain, Denmark and India) to which individuals' intakes of forty-five food parameters (consisting of nutrients, spices and whole foods) on which the DII is based could then be compared.

The steps involved in computing DII scores are described in Fig. 1. To summarise, FFQ-derived dietary data were used to calculate DII scores for all participants. First, they were linked to the world database described previously ${ }^{(22)}$. These then became the multipliers to express an individual's exposure relative to the 'standard global mean' as a $z$-score, which was computed by subtracting the 'standard global mean' from the amount reported and dividing this value by the 'global standard deviation'. To minimise the effect of 'right skewing', this value was then converted to a centred percentile score ${ }^{(22)}$ obtained by doubling and subtracting 1. Food parameterspecific DII scores were obtained by multiplying this score ${ }^{(22)}$. All of the food parameter-specific DII scores were then summed to create the overall DII score for each participant in the study.

For the current study, data on twenty-six of the forty-five DII food parameters could be derived from the FFQ, and were thus used for DII calculation. These included pro-inflammatory components (energy, carbohydrate, protein, fat, SFA, Fe, cholesterol) and anti-inflammatory components (alcohol, fibre, MUFA, PUFA, $n-3, n-6$, niacin, thiamin, riboflavin, $\mathrm{Mg}, \mathrm{Zn}$, vitamin A, vitamin $\mathrm{C}$, vitamin $\mathrm{E}$, folic acid, $\beta$-carotene, garlic and onions). The DII score can range from the maximum pro-inflammatory score of +7.98 to the minimum anti-inflammatory score of $-8 \cdot 87^{(22)}$. Positive DII scores indicate a pro-inflammatory diet and negative scores an anti-inflammatory diet. 
Review of articles published from 1950 to 2010 resulting in 1943 studies linking a total of 45 food parameters with inflammatory biomarkers.

A score for each food parameter was calculated giving:

+1 to each article if the effects were pro-inflammatory (significantly increased IL- $1 \beta$, IL-6, TNF- $\alpha$ or CRP, or decreased IL-4 or IL-10),

-1 if the effects were anti-inflammatory (significantly decreased IL- $1 \beta$, IL-6, TNF- $\alpha$ or CRP, or increased IL-4 or IL-10),

0 if the food parameter did not produce any significant change in the inflammatory marker.

The score for each food parameter was weighted according to the study design. The weights were 10 (experimental design), 8 (observational), 7 (case-control), 6 (cross-sectional), 5 (experimental with animal), 3 (cell culture).

A food parameter-specific overall inflammatory effect score was calculated by subtracting the anti-inflammatory fraction from the pro-inflammatory fraction. This score was corrected if the total weighted number of article was $<236$. In these cases the raw overall inflammatory score was multiplied by the total weighted number of articles divided by 236 .

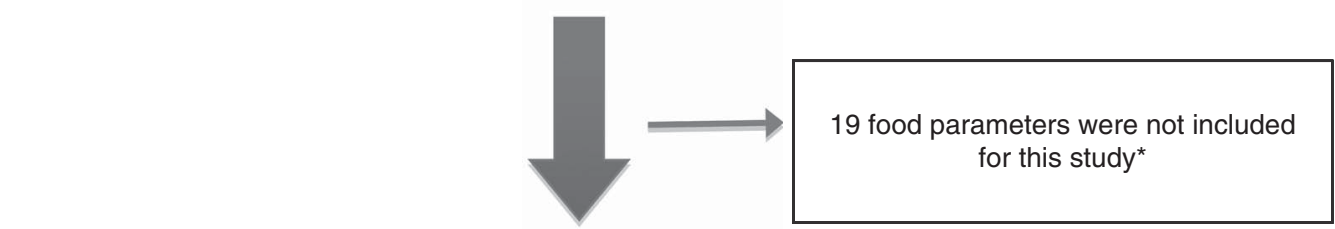

$Z$-score and centred-percentiles for each of the 26 available food parameters for each participant were calculated on the basis of the average and standard deviation for each food parameter obtained from the global database which was created from the consumption of the original 45 food parameters from 11 countries.

The centred percentile for each food parameter was multiplied by the respective 'overall food parameter-specific inflammatory effect score' to obtain the 'food parameter-specific Dll score'.

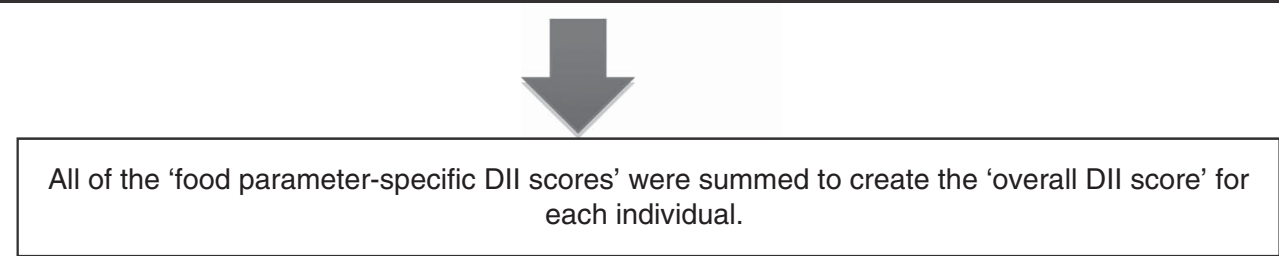

Fig. 1. Sequence of steps in creating the dietary inflammatory index (DII) in the Australian Longitudinal Study on Women's Health. * The missing food items were anthocyanin, eugenol, flavan-3-ols, flavones, flavonols, flavonones, isoflavones, caffeine, ginger, saffron, turmeric, vitamin $\mathrm{D}$, pepper, thyme and oregano, rosemary and Se. CRP, C-reactive protein. 
The DII method has been validated by comparing the DII scores with various inflammatory markers ${ }^{(30-32)}$. In addition, the DII score has been shown to be associated with glucose intolerance and dyslipidaemia components of the metabolic syndrome ${ }^{(33,34)}$, anthropometric measurements in $\operatorname{Spain}^{(35)}$, asthma in Australia ${ }^{(32)}$, bone mineral density among postmenopausal women in Iran ${ }^{(36)}$, two colorectal cancer case-control studies in Spain and Italy ${ }^{(37,38)}$ and in a cohort study of women in the USA ${ }^{(37,39)}$, and pancreatic and prostate cancers in Italy ${ }^{(40,41)}$

\section{Depressive symptoms}

Depressive symptoms were measured using the CESD-10 scale. This scale is constructed on the basis of self-reported responses to ten questions on whether, over the past week, women experienced symptoms associated with depression, such as worrying, sleeping difficulty and difficulty relaxing. The CESD-10 has a good test-re-test reliability and predictive validity when compared with the original twenty-item version ${ }^{(42)}$, and has high sensitivity (97-100\%) and specificity (84-93\%) for the screening of major depression in middle-aged and older adults ${ }^{(43)}$. Responses to the ten questions were reported using a four-point Likert scale ranging from 'rarely' (scored 0) to 'most of the time' (scored 3). Possible scores range from 0 to 30, with higher scores indicating more depressive symptoms. A CESD-10 score of $\geq 10$ was used to define the presence of depressive symptoms. Validation of the CESD-10 against the twenty-item version using a cut-off of $\geq 10$ has been shown to minimise false-positive results with little loss of sensitivity ${ }^{(42)}$. Incident depression was defined as new onset of depressive symptoms between survey 4 (2004) and survey 7 (2013).

\section{Assessment of covariates}

Self-reported information was collected at each survey on a range of socio-demographic variables, symptoms, lifestyle factors and health behaviours. Responses were categorised for the highest qualification obtained as 'no formal', '(higher) school certificate', 'trade/diploma' or 'university/higher degree'; for marital status as 'single/never married', 'married or de facto' or 'separated/divorced/widowed'; for night sweats as 'no' (never) or 'yes' (rarely/sometimes/often); for smoking as 'non-smoker', 'ex-smoker' or 'current smoker'; and for experience of stressful life events or diagnosis or treatment of depression since the previous survey as 'no' or 'yes'.

BMI was computed as self-reported weight $(\mathrm{kg})$ divided by the square of self-reported height $(\mathrm{m})$ and categorised as 'normal weight' $\left(\mathrm{BMI}<25 \mathrm{~kg} / \mathrm{m}^{2}\right)$, 'overweight' $\left(25 \leq \mathrm{BMI}<30 \mathrm{~kg} / \mathrm{m}^{2}\right)$ or 'obese' (BMI $\left.\geq 30 \mathrm{~kg} / \mathrm{m}^{2}\right)$. As only a limited proportion of women ( $1.5 \%$ ) were classified as 'underweight' (BMI $<18.5 \mathrm{~kg} / \mathrm{m}^{2}$ ), they were combined with the 'normal weight' group. Self-reported weight and height were validated in a subsample of 159 women (age 54-59 years). Both self-reported weight and height tended to be underestimated compared with measured values, with a mean difference of $0.95(95 \%$ CI $0.44,1.47) \mathrm{kg}$ and $0.67(95 \%$ CI 0.26, 1.08) cm, respectively. Agreement between BMI categories derived from self-reported and measured data was $84 \%{ }^{(44)}$.
Physical activity scores were derived from validated questions on frequency and duration of walking (for recreation or transport) and from questions on moderate- and vigorousintensity activity in the last week and categorised as 'sedentary/ low' (<600 metabolic equivalent (MET)-min/week), 'moderate' $(600 \leq \mathrm{MET}<1200 \mathrm{~min} /$ week $)$ or 'high' $(\geq 1200$ MET-min/ week $)^{(45)}$. Menopause status was determined using questions on hysterectomy, oophorectomy, hormone therapy and menstrual pattern and categorised as 'hysterectomy and/or oophorectomy', 'hormone therapy use', 'premenopausal', 'perimenopausal' or 'postmenopausal' ${ }^{(46)}$.

\section{Statistical analysis}

Baseline characteristics were described for women according to reporting of depressive symptoms at least once during followup and according to quartiles of the DII, and were compared using $t$ tests, ANOVA or $\chi^{2}$ tests. All descriptive statistics were weighted by area of residence to account for oversampling of women from rural and remote areas.

Generalised estimating equations were used to examine the prospective associations between the DII score (computed based on survey 3 data) and the incidence of depressive symptoms (survey 4-7). Log-binomial models or log-Poisson models (when log-binomial models did not converge) were used to estimate relative risks (RR) and 95\% CI. Models were adjusted for the time-varying confounders described above (survey 3-6). Model 1 adjusted for total energy intake, highest qualification completed, marital status, menopause status, hot flushes and experience of major personal illness or injury; model 2 additionally adjusted for lifestyle factors: smoking status, physical activity and BMI; and model 3 adjusted for depression diagnosis or treatment.

Factors including new onset of hot flushes, occupation, time spent socialising, performing active (walking or exercise) and passive (watching TV, reading, relaxing) leisure activities, and stressful life events including break-up of relationships or divorce and death of a close family member or friend were considered as potential confounders but not included in the final models as adjustments did not substantially change the effect estimates.

To test the robustness of our findings, additional analyses were performed. First, characteristics were compared with women included in the analysis and excluded because of missing data on confounders. Second, a multiple imputation analysis was performed to assess the influence of participant exclusions that resulted from missing data ${ }^{(47)}$. Third, in addition to examining the association between DII score and risk of depression in women with no history of depression before survey 3 based on a CESD-10 score of $\geq 10$, we examined the association in women with no history of doctor-diagnosed or treated depression. All statistical tests were conducted using a two-sided $5 \%$ level of significance.

\section{Results}

The mean DII score in this study was $1 \cdot 11$ (SD 1.54), which indicated a slightly pro-inflammatory diet. Table 1 describes 
Table 1. Baseline characteristics of middle-aged women according to reporting of depressive symptoms at least once during 12 years of follow-up, Australian Longitudinal Study on Women's Health, 2001 to $2013^{*}$

(Mean value and standard deviation; numbers and percentages, weighted by area of residence; $n$ 6438)

\begin{tabular}{|c|c|c|c|c|c|}
\hline \multirow[b]{2}{*}{ Baseline characteristics (survey 3 ) } & \multicolumn{2}{|c|}{$\begin{array}{c}\text { Depressive symptoms } \\
\text { (CESD-10 score } \geq 10)(n \text { 1156) }\end{array}$} & \multicolumn{2}{|c|}{$\begin{array}{c}\text { No depressive symptoms } \\
\text { (CESD-10 score }<10)(n \text { 5282) }\end{array}$} & \multirow[b]{2}{*}{$P \dagger$} \\
\hline & $n$ & $\%$ & $n$ & $\%$ & \\
\hline Age (years) & & & & & 0.37 \\
\hline Mean & & & & & \\
\hline SD & & & & & \\
\hline Highest qualification completed & & & & & $<0.0001$ \\
\hline No formal & 178 & 15.4 & 624 & 11.7 & \\
\hline (Higher) school certificate & 574 & $49 \cdot 6$ & 2430 & $45 \cdot 7$ & \\
\hline Trade/diploma & 205 & $17 \cdot 8$ & 1197 & $22 \cdot 5$ & \\
\hline University/higher degree & 200 & $17 \cdot 3$ & 1064 & $20 \cdot 0$ & \\
\hline Marital status & & & & & 0.21 \\
\hline Single/never married & 48 & 4.2 & 178 & 3.4 & \\
\hline Married or de facto & 947 & 81.9 & 4436 & 83.7 & \\
\hline Separated/divorced/widowed & 161 & 14.0 & 687 & $13 \cdot 0$ & \\
\hline Menopause status & & & & & 0.04 \\
\hline Hysterectomy and/or oophorectomy & 310 & $27 \cdot 0$ & 1261 & $23 \cdot 8$ & \\
\hline Hormone therapy use & 225 & $19 \cdot 6$ & 1065 & $20 \cdot 1$ & \\
\hline Premenopausal & 111 & 9.7 & 550 & $10 \cdot 4$ & \\
\hline Perimenopausal & 234 & $20 \cdot 4$ & 1036 & $19 \cdot 6$ & \\
\hline Postmenopausal & 267 & $23 \cdot 3$ & 1376 & $26 \cdot 0$ & \\
\hline BMI & & & & & 0.0001 \\
\hline Normal weight $\left(<25 \mathrm{~kg} / \mathrm{m}^{2}\right)$ & 508 & $45 \cdot 3$ & 2441 & 48.2 & \\
\hline Overweight $\left(25\right.$ to $\left.<30 \mathrm{~kg} / \mathrm{m}^{2}\right)$ & 345 & $30 \cdot 8$ & 1698 & 33.6 & \\
\hline Obese $\left(\geq 30 \mathrm{~kg} / \mathrm{m}^{2}\right)$ & 268 & $23 \cdot 9$ & 923 & $18 \cdot 2$ & \\
\hline Physical activity & & & & & 0.0003 \\
\hline Sedentary/low (<600 MET-min/week) & 630 & $55 \cdot 8$ & 2604 & $50 \cdot 6$ & \\
\hline Moderate (600 to $<1200$ MET-min/week) & 249 & $22 \cdot 0$ & 1132 & $22 \cdot 0$ & \\
\hline High ( $\geq 1200$ MET-min/week) & 251 & $22 \cdot 2$ & 1408 & $27 \cdot 4$ & \\
\hline Smoking & & & & & $<0.0001$ \\
\hline Non-smoker & 675 & 58.4 & 3422 & 64.6 & \\
\hline Ex-smoker & 286 & $24 \cdot 8$ & 1296 & 24.5 & \\
\hline Current smoker & 195 & $16 \cdot 9$ & 578 & $10 \cdot 9$ & \\
\hline Night sweats & 406 & $45 \cdot 1$ & 1548 & $39 \cdot 1$ & 0.001 \\
\hline Major personal illness or injury & 115 & $10 \cdot 0$ & 356 & $6 \cdot 7$ & 0.0001 \\
\hline
\end{tabular}

the distribution of several characteristics according to depression status. Women who developed depression during follow-up were more likely to have lower education, be obese, be sedentary/have low physical activity, be a current smoker, to have hot flushes, to have experienced major personal illness or injury and be less likely to be postmenopausal. Table 2 describes the distribution of characteristics across quartiles of DII scores. Women in the most pro-inflammatory group (quartile 4) were more likely to have lower education, be separated/divorced/widowed, be sedentary/have low physical activity and be current smokers.

The distribution of consumption of various nutrients and food items per day across quartiles of DII is shown in the online Supplementary Table S1. Most of the anti-inflammatory dietary components such as PUFA, dietary fibre, Zn, fruits, vegetables, fish and high-fibre grain foods decreased linearly across quartiles of DII. Similar trends were observed for intakes of total energy, total meat, and red and processed meat. Pro-inflammatory components whose intakes were higher among women in the fourth quartile were SFA, cholesterol, Ca, high-fat dairy products and added sugar.

Compared with the most pro-inflammatory group (4th quartile), the risk of developing depression was $26 \%$ lower in the most antiinflammatory group (1st quartile) $\left(\mathrm{RR}_{\mathrm{DII}}\right.$ quartile $1 v .4=0.74 ; 95 \%$ CI $\left.0.61,0.89, P_{\text {trend }}=0.001\right)$ for model $1,21 \%\left(\mathrm{RR}_{\text {quartile } 1 v .4}=\right.$ $0.79 ; 95 \%$ CI $\left.0.66,0.95, P_{\text {trend }}=0.03\right)$ for model 2 and $19 \%$ $\left(\mathrm{RR}_{\text {quartile } 1 v .4}=0.81 ; 95 \% \mathrm{CI} 0.69,0.96, P_{\text {trend }}=0.03\right)$ for model 3 (Table 3). The difference in the incidence of depression over 12 years between quartile 4 and quartile 1 of DII was $1.6 \%$.

Compared with women who were included in the analysis ( $n$ 6438), the $10 \%$ of women who were excluded because of missing confounding data ( $n$ 634) were more likely to have a pro-inflammatory diet, lower education, be separated/ divorced/widowed, be postmenopausal (surgical or natural), be obese, smoke tobacco, be sedentary or have low physical activity levels and have a history of major illness or injury. Incidence of depressive symptoms during follow-up did not differ for women who were included in the analysis compared with women who were excluded because of missing data (online Supplementary Table S2). Conclusions on the 
Table 2. Baseline characteristics of middle-aged women according to quartiles of the dietary inflammatory index (DII)*, Australian Longitudinal Study on Women's Health, 2001 to 2013

(Mean value and standard deviation; numbers and percentages, weighted by area of residence; $n 6438$ ) $\dagger$

\begin{tabular}{|c|c|c|c|c|c|c|c|c|c|}
\hline \multirow[b]{3}{*}{ Baseline characteristics (survey 3 ) } & \multicolumn{8}{|c|}{ Dietary inflammatory index } & \multirow[b]{3}{*}{$P \neq$} \\
\hline & \multicolumn{2}{|c|}{$\begin{array}{c}\text { Quartile } 1 \\
\text { (median -0.88; } \\
\text { IQR -1.60 to }-0.39) \\
(n 1610)\end{array}$} & \multicolumn{2}{|c|}{$\begin{array}{c}\text { Quartile } 2 \\
\text { (median 0.67; } \\
\text { IQR } 0.36 \text { to } 0.95) \\
(n 1609)\end{array}$} & \multicolumn{2}{|c|}{$\begin{array}{c}\text { Quartile } 3 \\
\text { (median 1.79; } \\
\text { IQR 1.50 to 2.04) } \\
(n 1609)\end{array}$} & \multicolumn{2}{|c|}{$\begin{array}{c}\text { Quartile } 4 \\
\text { (median 2.88; } \\
\text { IQR 2.59 to 3.23) } \\
(n 1610)\end{array}$} & \\
\hline & $n$ & $\%$ & $n$ & $\%$ & $n$ & $\%$ & $n$ & $\%$ & \\
\hline Age (years) & \multirow{2}{*}{\multicolumn{2}{|c|}{52}} & \multirow{2}{*}{\multicolumn{2}{|c|}{53}} & & & & & $0 \cdot 10$ \\
\hline Mean & & & & & \multicolumn{2}{|c|}{52} & \multicolumn{2}{|c|}{52} & \\
\hline SD & \multicolumn{2}{|c|}{1.4} & \multicolumn{2}{|c|}{1.4} & \multicolumn{2}{|c|}{1.5} & \multicolumn{2}{|c|}{1.4} & \\
\hline Highest qualification completed & & & & & & & & & 0.02 \\
\hline No formal & 202 & 13.5 & 158 & $10 \cdot 2$ & 200 & $12 \cdot 6$ & 211 & $13 \cdot 2$ & \\
\hline (Higher) school certificate & 651 & 43.4 & 730 & $47 \cdot 3$ & 735 & $46 \cdot 2$ & 770 & $48 \cdot 3$ & \\
\hline Trade/diploma & 348 & 23.2 & 351 & $22 \cdot 8$ & 342 & 21.5 & 313 & $19 \cdot 6$ & \\
\hline University/higher degree & 299 & $19 \cdot 9$ & 304 & $19 \cdot 7$ & 315 & $19 \cdot 8$ & 300 & $18 \cdot 8$ & \\
\hline Marital status & & & & & & & & & $<0.0001$ \\
\hline Single/never married & 47 & $3 \cdot 2$ & 61 & 4.0 & 64 & 4.0 & 46 & 2.9 & \\
\hline Married or de facto & 1298 & $86 \cdot 6$ & 1263 & $82 \cdot 3$ & 1336 & $84 \cdot 0$ & 1292 & $81 \cdot 0$ & \\
\hline Separated/divorced/widowed & 154 & $10 \cdot 3$ & 211 & $13 \cdot 8$ & 191 & $12 \cdot 0$ & 257 & $16 \cdot 1$ & \\
\hline Menopause status & & & & & & & & & 0.31 \\
\hline Hysterectomy and/or oophorectomy & 381 & $25 \cdot 6$ & 392 & $25 \cdot 6$ & 372 & 23.4 & 373 & 23.4 & \\
\hline Hormone therapy use & 284 & $19 \cdot 1$ & 296 & $19 \cdot 3$ & 336 & $21 \cdot 1$ & 327 & $20 \cdot 5$ & \\
\hline Premenopausal & 143 & $9 \cdot 6$ & 158 & $10 \cdot 3$ & 158 & 9.9 & 179 & 11.2 & \\
\hline Perimenopausal & 307 & $20 \cdot 6$ & 308 & $20 \cdot 0$ & 326 & 20.5 & 289 & $18 \cdot 1$ & \\
\hline Postmenopausal & 373 & $25 \cdot 1$ & 381 & $24 \cdot 8$ & 399 & $25 \cdot 1$ & 429 & $26 \cdot 9$ & \\
\hline BMI & & & & & & & & & 0.12 \\
\hline Normal weight $\left(<25 \mathrm{~kg} / \mathrm{m}^{2}\right)$ & 652 & $45 \cdot 1$ & 716 & $48 \cdot 6$ & 738 & $47 \cdot 2$ & 790 & 49.5 & \\
\hline Overweight $\left(25\right.$ to $\left.<30 \mathrm{~kg} / \mathrm{m}^{2}\right)$ & 488 & 33.8 & 468 & 31.8 & 538 & $34 \cdot 4$ & 515 & $32 \cdot 3$ & \\
\hline Obese $\left(\geq 30 \mathrm{~kg} / \mathrm{m}^{2}\right)$ & 305 & $21 \cdot 1$ & 290 & 19.7 & 287 & $18 \cdot 4$ & 290 & $18 \cdot 2$ & \\
\hline Physical activity & & & & & & & & & $<0.0001$ \\
\hline Sedentary/low (<600 MET-min/week) & 638 & 44.0 & 753 & $50 \cdot 3$ & 810 & $50 \cdot 9$ & 949 & 59.5 & \\
\hline Moderate (600 to $<1200 \mathrm{MET}-\mathrm{min} /$ week) & 357 & 24.6 & 345 & 23.0 & 360 & $22 \cdot 6$ & 293 & 18.4 & \\
\hline High ( $\geq 1200$ MET-min/week) & 454 & $31 \cdot 3$ & 400 & $26 \cdot 7$ & 421 & $26 \cdot 4$ & 352 & $22 \cdot 1$ & \\
\hline Smoking & & & & & & & & & $<0.0001$ \\
\hline Non-smoker & 1015 & $68 \cdot 1$ & 1015 & $66 \cdot 0$ & 1021 & $64 \cdot 2$ & 906 & $56 \cdot 8$ & \\
\hline Ex-smoker & 373 & $25 \cdot 0$ & 361 & 23.5 & 399 & $25 \cdot 1$ & 391 & 24.5 & \\
\hline Current smoker & 102 & 6.9 & 161 & $10 \cdot 5$ & 170 & $10 \cdot 7$ & 298 & $18 \cdot 7$ & \\
\hline Night sweats & 472 & $40 \cdot 7$ & 435 & $37 \cdot 6$ & 484 & $40 \cdot 0$ & 563 & $42 \cdot 4$ & $0 \cdot 12$ \\
\hline Major personal illness or injury & 120 & $8 \cdot 0$ & 112 & $7 \cdot 3$ & 92 & $5 \cdot 8$ & 129 & $8 \cdot 1$ & 0.04 \\
\hline
\end{tabular}

MET, total metabolic equivalent.

* Higher DII indicates a more pro-inflammatory diet, and lower DII indicates a more anti-inflammatory diet.

$\dagger$ Numbers may vary due to missing baseline values.

$\ddagger P$-values from ANOVA or $x^{2}$ test. All statistical tests were conducted using a two-sided $5 \%$ level of significance.

Table 3. Relative risks for associations between the dietary inflammatory index and incidence of depressive symptoms, Australian Longitudinal Study on Women's Health, 2001 to 2013

(Numbers and percentages; relative risks and $95 \%$ confidence intervals; $n$ 6438)

\begin{tabular}{|c|c|c|c|c|c|c|c|c|c|}
\hline \multirow[b]{2}{*}{ Dietary inflammatory index } & \multirow[b]{2}{*}{ Women $(n)$} & \multicolumn{2}{|c|}{ Cases } & \multicolumn{2}{|c|}{ Model $1^{*}$} & \multicolumn{2}{|c|}{ Model $2 \dagger$} & \multicolumn{2}{|c|}{ Model 3‡ } \\
\hline & & $n$ & $\%$ & Relative risk & $95 \% \mathrm{Cl}$ & Relative risk & $95 \% \mathrm{Cl}$ & Relative risk & $95 \% \mathrm{Cl}$ \\
\hline \multicolumn{10}{|l|}{ Quartiles } \\
\hline Quartile 1 & 1610 & 359 & $7 \cdot 4$ & 0.74 & $0.61,0.89$ & 0.79 & $0.66,0.95$ & 0.81 & $0.69,0.96$ \\
\hline Quartile 2 & 1609 & 378 & $7 \cdot 8$ & 0.84 & $0.71,0.98$ & 0.88 & $0.75,1.02$ & 0.88 & $0.76,1.03$ \\
\hline Quartile 3 & 1609 & 399 & 8.2 & 0.89 & $0.76,1.04$ & 0.93 & $0.79,1.09$ & 0.93 & $0.80,1.08$ \\
\hline Quartile 4 & 1610 & 437 & 9.0 & \multicolumn{2}{|c|}{1.00} & \multicolumn{2}{|c|}{1.00} & \multicolumn{2}{|c|}{1.00} \\
\hline$P$ & & & & \multicolumn{2}{|c|}{0.01} & \multicolumn{2}{|c|}{0.07} & \multicolumn{2}{|c|}{0.09} \\
\hline$P_{\text {for linear trend }}$ & & & & \multicolumn{2}{|c|}{0.001} & \multicolumn{2}{|c|}{0.03} & \multicolumn{2}{|c|}{0.03} \\
\hline
\end{tabular}

* Adjusted for total energy intake, highest qualification completed, marital status, menopause status, night sweats and major personal illness or injury.

$\dagger$ Additionally adjusted for lifestyle factors: smoking, physical activity and BMI.

$\ddagger$ Additionally adjusted for depression diagnosis or treatment.

association between DII and depression remained similar in analyses where missing confounding data were imputed (online Supplementary Table S3). Excluding women with a history of doctor-diagnosed or treated depression instead of a history of depressive symptoms based on a CESD-10 score of $\geq 10$ did not alter our findings (data not shown). 


\section{Discussion}

The present study, the largest prospective investigation on inflammatory potential of diet and depression to date in an Australian population, shows an inverse association between an anti-inflammatory dietary pattern - characterised by consumption of nutrients such as $n-3$ and $n-6$ PUFA, dietary fibre and food groups such as fruits, vegetables, meat, red meat, fish and high-fibre grain foods - and a lower risk of depression in a population-based study of middle-aged women.

In our study, most of the nutrient and food group distributions across quartiles of DII were as expected, but the distributions of total meat, processed meat and red meat were contrary to our expectation (levels increased across quartiles of DII). However, it should be noted that red meat is one among several other food items that influence inflammation. There are other food items such as vegetables, fruits and fish that exert strong antiinflammatory effects per unit exposure and their distributions are as expected. In addition, red meat is rich in nutrients including $\mathrm{Zn}$, vitamin $\mathrm{B}_{12}$ and $n$ - 6 fatty acids, all of which have an anti-inflammatory score with $\mathrm{DII}^{(48)}$. As the DII takes into account diet as a whole, and red meat eaters also consume vegetable components, spices and other anti-inflammatory foods, overall, their diet was more anti-inflammatory.

These results are consistent with a report from the Nurse's Health Study, where researchers observed a strong association between an inflammatory dietary pattern and depression ${ }^{(16)}$. Unlike the DII, which is empirically linked to findings in the literature, the inflammatory dietary pattern in that study was identified using reduced-rank regression, which in turn was related to plasma levels of inflammatory markers. To date, there has been only one other study, conducted in Spain, which has examined the association between the inflammatory potential of diet as determined by DII scores and depression. In that study, the hazards ratio for participants in the highest quintile of the DII (strongly pro-inflammatory) was 1.47 (95\% CI: $1 \cdot 17$, 1.85) compared with those in the lowest quintile, with a significant dose-response relationship $\left(P_{\text {for trend }}=0 \cdot 01\right)^{(23)}$.

A majority of our participants were well educated, with a high percentage of women in all DII quartiles having at least high school certificate education. It is also evident from the distribution of demographic data across quartiles of DII that women in quartile 4 were more likely to be separated/ divorced/widowed, report low levels of physical activity and currently smoking. We also observed decreased energy intake among women in quartile 4 compared with women in quartile 1. This is consistent with the fact that observations across all of the many studies we have conducted to date using the DII reveal two countervailing effects ${ }^{(39,49,50)}$. The first is a tendency to eat more of everything as one increases energy intake; this results in a positive correlation between energy intake and nutrient intake. The other is the 'healthy eater' effect (e.g., due to the intention of careful, health-conscious people to choose nutrient-dense, energy-sparse foods). This results in negative correlations between energy density and nutrient density. Thus far, we have observed that there is considerable variability in how these eating behaviours are distributed across different populations. In this population, it appears that the former effect of eating more of everything as one increases energy intake is stronger; hence, the mean energy intake is low in higher quartiles, which, in turn, means that the intakes of nutrients that are considered anti-inflammatory, such as vitamins and minerals, are also low.

Previously, in the ALSWH, we showed that increasing fruit consumption and adherence to the Mediterranean dietary pattern (garlic, peppers, mushrooms, salad greens, pasta and red wine) are protective against depression ${ }^{(17,18)}$. In a recent publication from the ALSWH, no association was observed between Australian Recommended Food Score and Mediterranean dietary pattern and depression, after adjusting for time-varying covariates $^{(51)}$. In addition, pooled results from two Australian cohorts showed people with lower intakes of $\mathrm{Zn}$ to be at higher risk of developing depression ${ }^{(52)}$.

Furthermore, a review of the literature on the role of $n$ - 3 fatty acids and depression supports an inverse association between the two ${ }^{(15)}$. In a large cohort study conducted in the USA, frequent consumption of sweetened beverages, especially diet drinks, was found to increase the risk of depression among older adults, whereas coffee consumption lowered the risk ${ }^{(13)}$. Various studies have been conducted examining the association between dietary patterns and depression. A systematic review conducted on twenty-one studies indicated that high intakes of fruit, vegetables, fish and wholegrains may be associated with a reduced depression risk ${ }^{(53)}$. In analyses of a cross-sectional study conducted in the USA, which explored the association between various dietary patterns and depression, a healthy dietary pattern characterised by increased fruit and vegetable intakes was inversely associated with depression; increased risk was observed with the sweet dietary pattern characterised by increased intake of cookies, ice cream and chocolates. However, in the same study, no increased risk was observed with an unhealthy pattern characterised by increased intake of fried potatoes, cheese, processed meat and red meat ${ }^{(54)}$. In a US cohort study conducted exclusively among women, no clear association was observed between any dietary patterns (prudent and Western) derived from factor analysis and depression $^{(55)}$. Several studies have shown dietary factors and dietary patterns not to be associated with depression - for example, in a cross-sectional study in Japan, no statistically significant linear association was observed for the intake of riboflavin, pyridoxine, cobalamin, total $n-3$ PUFA, $\alpha$-linolenic acid, EPA or $\mathrm{DHA}^{(56)}$. Nutrients such as $n-3$ and $\mathrm{Zn}$ and food items such as fruits and vegetables, which are rich in components such as flavonoids and vitamins, and garlic, which are antiinflammatory, produce more negative DII scores ${ }^{(22)}$.

Several previous studies have established the link between inflammation and depression ${ }^{(5,6,57,58)}$. Possible mechanisms for this observed association could be through the process of hyperleptinaemia or insulin resistance, which are observed in conditions such as obesity, the metabolic syndrome and type 2 diabetes mellitus and have been linked to inflammation processes, which are also common in depressive disorders ${ }^{(59)}$. Similarly, higher levels of cortisol have been observed among obese people, which in turn has resulted in higher hypothalamicpituitary-adrenal axis reactivity to psychological stress as well as physiological and pharmacological stimulation ${ }^{(60)}$. Indeed, the 
pro-inflammatory dietary components could induce sensitisation with increased activation of the inflammatory response system. It has been shown that in people with depression, inflammation is increased $^{(14,61)}$ and brain-derived neurotrophic factor is reduced $^{(62)}$

The strengths of our study include its relatively large sample size and its use of a validated and tested CESD scale to measure depressive symptoms. The prospective nature of the study minimises potential problems resulting from reverse causation.

Limitations include the loss to follow-up (approximately $10 \%$ ), which may have introduced selection bias. Results from multiple imputations to assess the impact of missing data from confounding variables did not alter the conclusions on the association between DII and depression. Another limitation of our study is that detailed dietary information was collected just once, and thus if changes in diet occurred from survey 4 to 6 over the 6-year period they could not be accounted for in this analysis. However, previous studies have reported that dietary pattern classification is moderately stable over long periods of time during adulthood ${ }^{(63-68)}$. For the current study, data were available on only twenty-six of the forty-five food parameters, and therefore missing information on the remaining nineteen food parameters could be a limitation. The missing food items were anthocyanin, eugenol, flavan-3-ols, flavones, flavonols, flavonones, isoflavones, caffeine, ginger, saffron, turmeric, vitamin $\mathrm{D}$, pepper, thyme and oregano, rosemary and Se. Several of these items are presumably not consumed frequently in the Australian population. Other food items such as flavonoids are more frequently consumed, and therefore might have influenced the DII scores computed in our study. Although we could not test and confirm this result in our cohort, other studies have observed relatively strong correlations between inflammatory biomarkers and DII when it was computed with fewer than thirty food parameters $(30,69,70)$. Another limitation could be the absence of evidence of DII scores being associated with inflammatory markers in this study, as no data on inflammatory markers were available. However, the DII has been validated previously with a variety of inflammatory markers in various studies ${ }^{(30,69,70)}$. Although the validity of the FFQ has been evaluated ${ }^{(71)}$, some degree of misclassification may exist in the dietary assessment. However, owing to the prospective nature of the study, the misclassification is unlikely to be differential. As such, the results probably would be biased towards the null. Another limitation of the FFQ is that it was validated on a small group of women of younger age than those included in the present study. Moreover, some of the results obtained could be biased because of residual confounding from measurement errors with factors such as education, marital status, physical activity and smoking status or unmeasured factors including psychosocial factors that might also be associated with depression (e.g., acquiescence $)^{(72)}$. We think that despite the small difference between quartile 4 and quartile 1, our findings may be relevant at a population level

In conclusion, anti-inflammatory diet as shown by lower DII scores was associated with a lower risk of developing depression in women from a population-based cohort study of middleaged Australian women. Therefore, promoting diets with increased consumption of anti-inflammatory foods such as vegetables and fruits could protect against developing depression. However, further studies including both cohort and intervention studies, analysing the link between diet, inflammation and depression, are warranted to elucidate the causal role of diet in the development of depression and other mental disorders.

\section{Acknowledgements}

The research on which this paper is based was conducted as part of the ALSWH, the University of Newcastle and the University of Queensland. The authors are grateful to the Australian Government Department of Health for funding and to the women who provided the survey data. The authors thank Professor Graham Giles of the Cancer Epidemiology Centre of Cancer Council Victoria for permission to use the DQES (version 2), Melbourne: Cancer Council Victoria, 1996.

N. S. and J. R. H. were supported by grant number R44DK103377 from the United States National Institute of Diabetes and Digestive and Kidney Diseases. G. D. M. is supported by an Australian Research Council Future Fellowship (FT120100812). None of the funding organisations had any role in the design, analysis or writing of this article.

G. D. M. designed and conducted the study; N. S. calculated the DII scores and wrote the first draft of the manuscript; D. A. J. M. S. performed analyses and worked on the methods and results sections of the manuscript. N. S., D. A. J. M. S., J. R. H. and G. D. M. provided suggestions and revised the manuscript. All the authors approved the final version of the manuscript.

J. R. H. Owns controlling interest in Connecting Health Innovations LLC (CHI), a company planning to licence the right to his invention of the DII from the University of South Carolina in order to develop computer and smart phone applications for patient counselling and dietary intervention in clinical settings. N. S. is an employee of CHI.

\section{Supplementary material}

For supplementary material/s referred to in this article, please visit http://dx.doi.org/doi:10.1017/S0007114516002853

\section{References}

1. World Health Organization (2011) Mental health - disorders management 2011. http://www.who.int/mental_health/ management/depression/definition/en/.2011 (accessed May 2015).

2. Whiteford HA, Degenhardt L, Rehm J, et al. (2010) Global burden of disease attributable to mental and substance use disorders: findings from the Global Burden of Disease Study. Lancet 382, 1575-1586.

3. Ford DE \& Erlinger TP (2004) Depression and C-reactive protein in US adults: data from the third national health and nutrition examination survey. Arch Intern Med 164, 1010-1014.

4. Albert PR (2015) Why is depression more prevalent in women? J Psychiatry Neurosci 40, 219-221. 
5. Hood KK, Lawrence JM, Anderson A, et al. (2012) Metabolic and inflammatory links to depression in youth with diabetes. Diabetes Care 35, 2443-2446.

6. Doyle TA, de Groot M, Harris T, et al. (2013) Diabetes, depressive symptoms, and inflammation in older adults: results from the health, aging, and body composition study. J Psychosom Res 75, 419-424.

7. Pasco JA, Nicholson GC, Williams LJ, et al. (2010) Association of high-sensitivity C-reactive protein with de novo major depression. Br J Psychiatry 197, 372-377.

8. Halaris A (2013) Inflammation, heart disease, and depression. Curr Psychiatry Rep 15, 400.

9. de Mello VD, Schwab U, Kolehmainen M, et al. (2011) A diet high in fatty fish, bilberries and wholegrain products improves markers of endothelial function and inflammation in individuals with impaired glucose metabolism in a randomised controlled trial: the Sysdimet study. Diabetologia 54, 2755-2767.

10. Khoo J, Piantadosi C, Duncan R, et al. (2011) Comparing effects of a low-energy diet and a high-protein low-fat diet on sexual and endothelial function, urinary tract symptoms, and inflammation in obese diabetic men. J Sex Med 8, $2868-2875$.

11. Luciano M, Mottus R, Starr JM, et al. (2012) Depressive symptoms and diet: their effects on prospective inflammation levels in the elderly. Brain Behav Immun 26, 717-720.

12. Wood AD, Strachan AA, Thies F, et al. (2014) Patterns of dietary intake and serum carotenoid and tocopherol status are associated with biomarkers of chronic low-grade systemic inflammation and cardiovascular risk. Br J Nutr 112, 1341-1352.

13. Guo XG, Park Y, Freedman ND, et al. (2014) Sweetened beverages, coffee, and tea and depression risk among older US adults. PLOS ONE 9, e94715.

14. Hegarty BD \& Parker GB (2011) Marine omega-3 fatty acids and mood disorders - linking the sea and the soul. 'Food for Thought' I. Acta Psychiatr Scand 124, :42-51.

15. Liperoti R, Landi F, Fusco O, et al. (2009) Omega-3 polyunsaturated fatty acids and depression: a review of the evidence. Curr Pharm Design 15, 4165-4172.

16. Lucas M, Chocano-Bedoya P, Shulze MB, et al. (2014) Inflammatory dietary pattern and risk of depression among women. Brain Behav Immun 36, 46-53.

17. Mihrshahi S, Dobson AJ \& Mishra GD (2015) Fruit and vegetable consumption and prevalence and incidence of depressive symptoms in mid-age women: results from the Australian longitudinal study on women's health. Eur J Clin Nutr 69, 585-591.

18. Rienks J, Dobson AJ \& Mishra GD (2013) Mediterranean dietary pattern and prevalence and incidence of depressive symptoms in mid-aged women: results from a large community-based prospective study. Eur J Clin Nutr 67, $75-82$.

19. Sanchez-Villegas A, Delgado-Rodriguez M, Alonso A, et al. (2009) Association of the Mediterranean dietary pattern with the incidence of depression: the Seguimiento Universidad de Navarra/University of Navarra follow-up (SUN) cohort. Arch Gen Psychiatry 66, 1090-1098.

20. Akbaraly TN, Brunner EJ, Ferrie JE, et al. (2009) Dietary pattern and depressive symptoms in middle age. Br J Psychiatry 195, 408-413.

21. Le Port A, Gueguen A, Kesse-Guyot E, et al. (2012) Association between dietary patterns and depressive symptoms over time: a 10-year follow-up study of the GAZEL cohort. PLOS ONE 7, e51593.

22. Shivappa N, Steck SE, Hurley TG, et al. (2014) Designing and developing a literature-derived, population-based dietary inflammatory index. Public Health Nutr 17, 1689-1696.
23. Sanchez-Villegas A, Ruiz-Canela M, de la Fuente-Arrillaga C, et al. (2015) Dietary inflammatory index, cardiometabolic conditions and depression in the Seguimiento Universidad de Navarra cohort study. Br J Nutr 114, 1471-1479.

24. Brown WJ, Bryson L, Byles JE, et al. (1998) Women's Health Australia: recruitment for a national longitudinal cohort study. Women Health 28, 23-40.

25. Lee C, Dobson AJ, Brown WJ, et al. (2005) Cohort profile: the Australian Longitudinal Study on Women's Health. Int J Epidemiol 34, 987-991.

26. Ireland P, Jolley D, Giles G, et al. (1994) Development of the Melbourne FFQ: a food frequency questionnaire for use in an Australian prospective study involving an ethnically diverse cohort. Asia Pac J Clin Nutr 3, $19-31$.

27. Hodge A, Patterson AJ, Brown WJ, et al. (2000 Dec) The Anti Cancer Council of Victoria FFQ: relative validity of nutrient intakes compared with weighed food records in young to middle-aged women in a study of iron supplementation. Aust $N Z$ J Public Health 24, 576-583.

28. Lewis JMG \& Hunt A (1995) NUTTAB95 Nutrient Data Table for Use in Australia. Canberra, Australia: Australian Government Publishing Service.

29. Shivappa N, Steck SE, Hurley TG, et al. (2014) A populationbased dietary inflammatory index predicts levels of C-reactive protein in the Seasonal Variation of Blood Cholesterol Study (SEASONS). Public Health Nutr 17, 1825-1833.

30. Tabung FK, Steck SE, Zhang J, et al. (2015) Construct validation of the dietary inflammatory index among postmenopausal women. Ann Epidemiol 25, 398-405.

31. Wirth MD, Burch J, Shivappa N, et al. (2014) Association of a dietary inflammatory index with inflammatory indices and metabolic syndrome among police officers. J Occup Environ Med 56, 986-989.

32. Wood LG, Shivappa N, Berthon BS, et al. (2015) Dietary inflammatory index is related to asthma risk, lung function and systemic inflammation in asthma. Clin Exp Allergy $\mathbf{4 5}$, 177-183.

33. Alkerwi A, Sauvageot N, Malan L, et al. (2015) Association between nutritional awareness and diet quality: evidence from the observation of cardiovascular risk factors in Luxembourg (ORISCAV-LUX) study. Nutrients 7, 2823-2838.

34. Wirth MD, Burch J, Shivappa N, et al. (2014)) Association of a dietary inflammatory index with inflammatory indices and metabolic syndrome among police officers. J Occup Environ Med 56, 986-989.

35. Ruiz-Canela M, Zazpe I, Shivappa N, et al. (2015) Dietary inflammatory index and anthropometric measures of obesity in a population sample at high cardiovascular risk from the PREDIMED (PREvencion con DIeta MEDiterranea) trial. $\mathrm{Br} J$ Nutr 113, 984-995.

36. Ge I, Rudolph A, Shivappa N, et al. (2015) Dietary inflammation potential and postmenopausal breast cancer risk in a German case-control study. Breast 24, 491-496.

37. Zamora-Ros R, Shivappa N, Steck SE, et al. (2015) Dietary inflammatory index and inflammatory gene interactions in relation to colorectal cancer risk in the Bellvitge colorectal cancer case-control study. Genes Nutr 10, 447.

38. Shivappa N, Zucchetto A, Montella M, et al. (2015) Inflammatory potential of diet and risk of colorectal cancer in a case-control study from Italy. $\mathrm{Br} J$ Nutr 114, $152-158$

39. Shivappa N, Prizment AE, Blair CK, et al. (2014) Dietary inflammatory index and risk of colorectal cancer in the Iowa Women's Health Study. Cancer Epidemiol Biomarkers Prev 23, 2383-2392. 
40. Shivappa N, Bosetti C, Zucchetto A, et al. (2015) Association between dietary inflammatory index and prostate cancer among Italian men. BrJ Nutr 113, 278-283.

41. Shivappa N, Bosetti C, Zucchetto A, et al. (2015) Dietary inflammatory index and risk of pancreatic cancer in an Italian case-control study. Br J Nutr 113, 292-298.

42. Andresen EM, Malmgren JA, Carter WB, et al. (1994) Screening for depression in well older adults: evaluation of a short form of the CES-D (Center for Epidemiologic Studies Depression Scale). Am J Prev Med 10, 77-84.

43. Irwin M, Artin KH \& Oxman MN (1999) Screening for depression in the older adult: criterion validity of the 10-item Center for Epidemiological Studies Depression Scale (CES-D). Arch Intern Med 159, 1701-1704.

44. Burton NW, Brown W \& Dobson A (2010) Accuracy of body mass index estimated from self-reported height and weight in mid-aged Australian women. Aust $N Z$ J Public Health 34, 620-623.

45. Brown WJ, Burton NW, Marshall AL, et al. (2008) Reliability and validity of a modified self-administered version of the Active Australia physical activity survey in a sample of mid-age women. Aust N Z J Public Health 32, 535-541.

46. Berecki-Gisolf J, Begum N \& Dobson AJ (2009) Symptoms reported by women in midlife: menopausal transition or aging? Menopause 16, 1021-1029.

47. Berglund PA (2010) An Introduction to Multiple Imputation of Complex Sample Data Using SAS v9.2. Cary, NC.

48. McAfee AJ, McSorley EM, Cuskelly GJ, et al. (2010) Red meat consumption: an overview of the risks and benefits. Meat Sci 84, $1-13$.

49. Ruiz-Canela M, Zazpe I, Shivappa N, et al. (2015) Dietary inflammatory index and anthropometric measures of obesity in a population sample at high cardiovascular risk from the PREDIMED (PREvencion con DIeta MEDiterranea) trial. $\mathrm{Br} \mathrm{J}$ Nutr 113, 984-995.

50. Shivappa N, Harris H, Wolk A, et al. (2016) Association between inflammatory potential of diet and mortality among women in the Swedish Mammography Cohort. Eur J Nutr 55, 1891-1900.

51. Lai JS, Oldmeadow C, Hure AJ, et al. (2016) Longitudinal diet quality is not associated with depressive symptoms in a cohort of middle-aged Australian women. Br J Nutr 115 842-850.

52. Vashum KP, McEvoy M, Milton AH, et al. (2014) Dietary zinc is associated with a lower incidence of depression: findings from two Australian cohorts. J Affect Disord 166, 249-257.

53. Lai JS, Hiles S, Bisquera A, et al. (2014 Jan) A systematic review and meta-analysis of dietary patterns and depression in community-dwelling adults. Am J Clin Nutr 99, 181-197.

54. Dipnall JF, Pasco JA, Meyer D, et al. (2015) The association between dietary patterns, diabetes and depression. J Affect Disorders 174, 215-224.

55. Chocano-Bedoya PO, O'Reilly EJ, Lucas M, et al. (2013) Prospective study on long-term dietary patterns and incident depression in middle-aged and older women. Am J Clin Nutr 98, 813-820.
56. Murakami K, Mizoue T, Sasaki S, et al. (2008) Dietary intake of folate, other B vitamins, and omega-3 polyunsaturated fatty acids in relation to depressive symptoms in Japanese adults. Nutrition 24, 140-147.

57. Chocano-Bedoya PO, Mirzaei F, O'Reilly EJ, et al. (2014) C-reactive protein, interleukin-6, soluble tumor necrosis factor alpha receptor 2 and incident clinical depression. I Affect Disord 163, 25-32.

58. Au B, Smith KJ, Gariepy G, et al. (2014) C-reactive protein, depressive symptoms, and risk of diabetes: results from the English Longitudinal Study of Ageing (ELSA). J Psychosom Res 77, 180-186.

59. Flehmig G, Scholz M, Kloting N, et al. (2014) Identification of adipokine clusters related to parameters of fat mass, insulin sensitivity and inflammation. PLOS ONE 9, e99785.

60. Bjorntorp P (1993) Visceral obesity: a 'civilization syndrome'. Obes Res 1, 206-222.

61. Parker G, Gibson NA, Brotchie H, et al. (2006) Omega-3 fatty acids and mood disorders. Am J Psychiatry 163, 969-978.

62. Belmaker RH \& Agam G (2008) Major depressive disorder. $N$ Engl J Med 358, 55-68.

63. Jain M, Howe GR, Harrison L, et al. (1989) A study of repeatability of dietary data over a seven-year period. $A m J$ Epidemiol 129, 422-429.

64. Jensen OM, Wahrendorf J, Rosenqvist A, et al. (1984) The reliability of questionnaire-derived historical dietary information and temporal stability of food habits in individuals. $A m J$ Epidemiol 120, 281-290.

65. Lindsted KD \& Kuzma JW (1989) Long-term (24-year) recall reliability in cancer cases and controls using a 21-item food frequency questionnaire. Nutr Cancer 12, 135-149.

66. Mursu J, Steffen LM, Meyer KA, et al. (2013) Diet quality indexes and mortality in postmenopausal women: the Iowa Women's Health Study. Am J Clin Nutr 98, 444-453.

67. Sijtsma FP, Meyer KA, Steffen LM, et al. (2012 Mar) Longitudinal trends in diet and effects of sex, race, and education on dietary quality score change: the Coronary Artery Risk Development in Young Adults study. Am J Clin Nutr 95, 580-586.

68. Thompson FE, Metzner HL, Lamphiear DE, et al. (1990) Characteristics of individuals and long term reproducibility of dietary reports: the Tecumseh Diet Methodology Study. J Clin Epidemiol 43, 1169-1178.

69. Shivappa N, Hebert JR, Rietzschel ER, et al. (2015) Associations between dietary inflammatory index and inflammatory markers in the Asklepios Study. Br J Nutr 113, 665-671.

70. Shivappa N, Steck SE, Hurley TG, et al. (2014) A populationbased dietary inflammatory index predicts levels of C-reactive protein in the Seasonal Variation of Blood Cholesterol Study (SEASONS). Public Health Nutr 17, 1825-1833.

71. Hodge A, Patterson AJ, Brown WJ, et al. (2000) The Anti Cancer Council of Victoria FFQ: relative validity of nutrient intakes compared with weighed food records in young to middle-aged women in a study of iron supplementation. Australian New Zealand J Public Health 24, 576-583.

72. Edwards AL (1961) Social desirability or acquiescence in the MMPI? A case study with the SD scale. J Abnormal Soc Psychol 63, 351-359. 